\title{
Alfa-Pinen, Terpineol, Sineol, Linelol ve Kamforun Bakteriyel Hücreler Arası İletişim Sistemi Üzerine İnhibitör Etkileri
}

\author{
Erdi DOĞRU1, Seyhan ULUSOY*1 \\ ${ }^{1}$ Süleyman Demirel Üniversitesi, Fen Edebiyat Fakültesi, Biyoloji Bölümü, 32260, Isparta
}

(Alınış / Received: 01.06.2016, Kabul / Accepted: 30.06.2016, Online Yayınlanma / Published Online: 25.07.2016)

\author{
Anahtar Kelimeler \\ Pseudomonas aeruginosa, \\ Hücreler arası iletişim, \\ Alfa pinen, \\ Terpineol, \\ Sineol, \\ Linelol
}

\begin{abstract}
Özet: Pek çok Gram negatif patojen bakteri çeșitli virülens faktörlerinin üretiminin genetik seviyede kontrolünü N-Açil homoserin lakton aracılı hücreler arası iletişim sistemini kullanarak sağlar. Bu nedenle bu hücreler arası iletişim sisteminin engellenmesi veya modifiye edilmesi, bu sistemi yeni terapötiklerin keșfi için cazip bir hedef haline getirmektedir. Hücreler arası iletişim sistemi inhibitörü, bitkisel kökenli pek çok doğal ürün bulunmaktadır. Bu çalışmada defne, adaçayı, mersin ve ardıç uçucu yağlarının bakterilerdeki hücreler arası iletişim sistemi üzerine engelleyici özellikleri incelenmiş ve bu yağ örneklerinin majör bileșenleri GC-MS ile belirlenmiştir. Alfa pinen, terpineol, sineol, linelol ve kamforun (yağ örneklerinin majör bileșenleri) hücreler arası iletişim sistemi üzerine inhibitör etkileri $C$. violaceum, 026, C. violaceum VIR07, Pseudomonas aeruginosa PA01, P. aeruginosa PAC-1 kullanılarak araştırılmıştır. Sonuçlar alfa pinen, terpineol, sineol, linelol ve kamforun $C$. violaceum, $026, C$. violaceum VIR07 suşunda viyolasin üretiminin hem de, $P$. aeruginosa PA01 ve $P$. aeruginosa PAC-1 klinik izolatında piyosiyanin, elastaz üretimi ve kayma hareketini önemli derecede inhibe ettiğini göstermiştir. Çalışmanın sonuçları alfa pinen, terpieneol, sineol, linelol ve kamforun, $C$ violaceum ve $P$. aeruginosa için hücreler arası iletişim sistemi üzerine inhibitör etkileri bulunduğu tespit edilmiştir.
\end{abstract}

\section{Quorum Sensing Inhibitory Activities of Alpha-Pinene, Terpineol, Cineole, Linalool and Camphor}

\section{Keywords}

Pseudomonas aeruginosa, Quorum sensing, Alpha pinene,

Terpineol,

Cineole,

Linalool

\begin{abstract}
Many pathogenic Gram negative bacteria often use N-Acyl homoserine lactone mediated cell to cell communication (quorum sensing) system to control the gene expression of various virulence factors. Thus blocking or manipulating this system makes it an attractive target for discovery of new therapeutics. There are a number of plant-based natural products as quorum sensing inhibitors.. In this study, QS inhibitory potential of laurus, salvia, myrtus and juniperus essential oils were screened and compositions of oils were analysed by GC-MS. The anti-quorum sensing activity of alpha pinene, terpineol, cineole, linalool and camphor (major components of oils) tested against using Chromobacterium violaceum strain CV026, C. violaceum strain VIR07, Pseudomonas aeruginosa PA01, P. aeruginosa PAC-1. Results showed that alpha pinene, terpineol, cineole, linalool and camphor significantly inhibited violacein production in $C$. violaceum $026, C$. violaceum VIR07, as well as the elastase, pyocyanin production, swarming motilty in $P$. aeruginosa PA01, P. aeruginosa PAC-1. Our findings demonstrated that alpha pinene, terpineol, cineole, linalool and camphor have potential as inhibitors of quorum sensing system in $C$ violaceum and $P$. aeruginosa.
\end{abstract}

\section{Giriş}

Bakteriler çevreleriyle ve birbirleriyle iletişim yeteneğine sahip sosyal organizmalardır[1]. Bakterilerin iletişim dili, onların üreterek büyüme ortamına saldıkları sinyal moleküllerinden oluşmaktadır. Bu moleküllerinin konsantrasyonunun bakteriler tarafından algılanmasıyla, bakteriler birbirlerini algılayarak pek çok özelliğin topluluk halinde gerçekleştirilmesini kontrol edebilmektedir. 
$\mathrm{Bu}$ sistem "Quorum Sensing" (Çevreyi/çoğunluğu Algılama Sistemi) olarak bilinmektedir[2]. Bu sistem aracılığıyla çeşitli bakteriyel davranışların (biyofilm oluşumu, antibiyotik sentezi, çeşitli virülens genlerinin ifadesi, simbiyoz) kontrol edildiği bilinmektedir [3]. Gram-negatif firsatçı patojenlerin çoğu, yüksek yapılı organizmalarda kolonize olmaları sırasında, bu sinyal moleküllerini kullanarak popülasyon davranışlarını düzenlerler[4]. Böylece bu sistem, bakterilere konak üzerinde popülasyon yoğunluklarını algılayarak, eşik hücre yoğunluğuna ulașıldığında virülens faktörlerinin üretimini genetik seviyede kontrol etmelerini sağlar [5, 6]. Fırsatçı bir insan patojeni olan Pseudomonas aeruginosa, çeşitli enfeksiyonlar (yanık, AIDS, kanser) sonucu bağışıklık sistemi baskılanmış bireylerde veya kistik fibroz hastalarının akciğerlerinde ciddi enfeksiyonlara neden olmaktadır. $P$. aeruginosa'da virülens faktörlerinin üretimi (elastaz, piyosiyanin, proteaz) ve biyofilm oluşumu $\mathrm{N}$-açil homoserin lakton (HSL) sinyal molekülü aracıl çevreyi algılama sistemi tarafından düzenlenmektedir[7, 8].

Yine Gram(-) firsatçı bir patojen olan Chromobacterium violaceum N-hekzanoyil-HSL (C6HSL) aracı çevreyi algılama sistemini kullanarak viyolasin üretimini düzenlemektedir [9]. Yine $C$. violaceum'un sinyal molekülü üretemeyen mutant suşları $C$. violaceum VIR07 ve $C$. violaceum 026 , diğer bakterilerin açil homoserin lakton molekülleri üretimlerini test için kullanılmaktadır $[9,10]$. Bakteriler çevreyi algılama sistemini kullanarak, ürettikleri sinyal molekülleri aracılığı ile iletişim kurmakta, bulundukları ortamda hücre sayılarını takip ederek, yeter çoğunluğa ulaştıkları anda virülens faktörlerinin sentezi gibi kritik moleküllerin üretimi için gerekli gen ekspresyonlarını tetiklemektedir. Böylece patojen bakteriler, konağın bağışıklık sistemini zamanından önce uyarmayarak başarılı bir enfeksiyon sürecinin gelişmesini sağlamaktadırlar.

Çoklu ilaç direncine sahip bakterilerin artışı, enfeksiyonların tedavisi için yeni yaklaşımların geliştirilmesini zorunlu kılmaktadır. $P$. aeruginosa'da biyofilm oluşumu dahil birçok virülens faktörünün üretiminin çevreyi algılama sistemi ile düzenlenmesi, yeni antibakteriyel moleküllerin geliştirilebilmesi için ilginin çevreyi algılama sistemi üzerine yoğunlaşmasına neden olmuştur[1]. Günümüzde, bakteriyel enfeksiyonların tedavisi için kullanılan antibiyotikler, bakteriyi doğrudan öldürerek veya çoğalmalarını engelleyerek etki gösterdikleri için hızla dirençli bakteriyel popülasyonların gelişmesine neden olmaktadır. Bu da, kullanılan antibiyotiklerin giderek etkisiz kalması, dolayısıyla hastalıkların tam anlamıla tedavi edilememesi, direncin yayılması ve ekonomik kayıplar ile sonuçlanmaktadır. Bu nedenle dünya genelinde pek çok araștırma grubu tarafından bakteriyel enfeksiyon hastalıkları engellemek veya onların tedavisinde yeni stratejiler tespit etmek için önemli çalışmalar yapılmaktadır. $\mathrm{Bu}$ çalışmalar özellikle bakteri hücreleri arasında iletişimin engellenmesi veya modifiye edilmesiyle, çevreyi algılama sistemini bloke eden moleküllerin tespit edilmesi üzerine yoğunlaşmıștır[11]. Bu yolla, önemli patojenlerin enfeksiyon oluşturma yeteneklerinin zayıflatılması ve bakteriyel enfeksiyonların kontrol altında tutulması hedeflenmektedir.

Günümüzde alternatif tıbba duyulan ilginin artması nedeniyle, kullanılan bitkisel ürünlerin antikanser, antibakteriyel, antienflamatuvar vs. etkilerini konu alan çok sayıda çalıșma yapılmaktadır[12, 13]. Ayrıca çeşitli bitkisel kökenli ürünlerin kullanabilirliği açısından, bilimsel çalışmalar konusunda eksikler mevcuttur.

$\mathrm{Bu}$ çalışma kapsamında piyasadan temin edilen adaçayı, mersin, defne, uçucu yağ örneklerinin potansiyel çevreyi algılama sistemi üzerine inhibitör etkileri incelenmiştir. Bunun için öncelikle $C$. violaceum VIR07 ve $C$. violaceum CV026 biyomonitör suşları kullanılarak yağ örneklerinin, çevreyi algılama sistemine potansiyel inhibitör etkileri incelenmiştir. Daha sonra antibakteriyel etkilerini belirlenmesi amacıyla yağ örneklerinin minimum inhibisyon konsantrasyonları belirlenmiș ve GC-MS ile örneklerin uçucu bileşen analizleri yapılarak, yüzdece fazla bulunan etken maddeler tespit edilmiştir. Bunlardan alfapinen, terpineol, sineol, kamfor ve linelolun önemli bir insan patojeni olan P. aeruginosa PA01, $P$. aeruginosa PAC-1 klinik izolatında, $C$. violaceum 026, C. violaceum VIR07 suşunda çevreyi algllama sistemi üzerine etkileri, elastaz, piyosiyanin, biyofilm üretimi, viyolasin pigmenti ve kayma hareketi üzerine etkileri araștırılmıștır.

\section{Materyal ve Metot}

\subsection{Bakteriyel suşlar}

Deneylerde kullanılan suşlar (Tablo 1) Luria Bertani (LB) sıvı besiyerine ekilmiş ve $30^{\circ} \mathrm{C}$ veya $37^{\circ} \mathrm{C}$ de 1 gece inkübe edilmiștir. İnkübasyon sonunda kültür ortamına $\% 10(\mathrm{v} / \mathrm{v})$ gliserol ilave edilerek kullanılıncaya kadar $-80^{\circ} \mathrm{C}^{\prime}$ de muhafaza edilmiştir.

Tablo 1. Çalışma sırasında kullanılan suşlar

\begin{tabular}{|c|c|c|}
\hline Suş Adı & Özellik & Kaynak \\
\hline $\begin{array}{c}\text { P. aeruginosa } \\
\text { PA01 }\end{array}$ & PT5 orijinal tip & $\begin{array}{c}\text { SDÜ Biyoloji } \\
\text { Bölümü Stoğu }\end{array}$ \\
\hline $\begin{array}{c}\text { P. aeruginosa PAC- } \\
1\end{array}$ & $\begin{array}{c}\text { Klinik izolat (Kan } \\
\text { kültürü) }\end{array}$ & $\begin{array}{c}\text { SDÜ Biyoloji } \\
\text { Bölümü Stoğu }\end{array}$ \\
\hline C. violaceum 026 & $\begin{array}{c}\text { Viyolasin pigmenti } \\
\text { üretimi }\end{array}$ & $\begin{array}{c}\text { SDÜ Biyoloji } \\
\text { Bölümü Stoğu }\end{array}$ \\
\hline C. violaceum VIR07 & $\begin{array}{c}\text { Viyolasin pigmenti } \\
\text { üretimi }\end{array}$ & $\begin{array}{c}\text { SDÜ Biyoloji } \\
\text { Bölümü Stoğu }\end{array}$ \\
\hline
\end{tabular}

\subsection{Uçucu yağ örnekleri}

Uçucu yağ örnekleri piyasadan temin edilerek kullanılmıştır. 


\subsection{GC-MS analizi}

Uçucu yağ örneklerinin Shimadzu GC-MS QP 5050 (Kyoto, Japan) Gaz kromatografi-Külte Spektroskopisi (GC-MS) sistemi kullanılarak analiz gerçekleştirilmiştir. Analiz sırasında CP WAX 52 kapiler kolon (50 m x0,32 mm ID, df: 1,2) (Varian), taşıyıcı gaz olarak helyum kullanılmıştır. Enjeksiyon hacmi $1 \mu \mathrm{L}$ dir. GC sıcaklık programı: Fırın başlangıç sıcaklığı $60^{\circ} \mathrm{C}$ olup dakikada $2^{\circ} \mathrm{C}^{\prime}$ lik artış ile bu sicaklıktan $220^{\circ} \mathrm{C}$ 'ye yükselmiştir. $220^{\circ} \mathrm{C}^{\prime}$ de 20 dakika bekletilmiștir. Kolon olarak, Cp WAX 52 CB $(50$ m* $0,32 \mathrm{~mm}$ ) kullanılmıștır. Dedektör ve enjektör sıcaklığ $250^{\circ} \mathrm{C}$ şeklindedir.

2.4. Alfapinen, terpineol, sineol, kamfor ve lineolun antibakteriyel özelliklerinin incelenmesi

Uçucu yağ örneklerinin anti-bakteriyel özellikleri $C$. violaceum 026, C. violaceum VIR07, P. aeruginosa PA01, $P$. aeruginosa PAC-1 için agar difüzyon tekniği kullanılarak test edilmiştir. Ayrıca yağ örneklerinin MIK seviyeleri broth dilüsyon metodu ile belirlenmiştir [13].

İnkübasyon sonrasında tüm suşlar ve izolatlar için, gözle görülebilir bulanıklığın olmadığı en düşük derişimdeki yağın bulunduğu tüp MiK değeri olarak kabul edilmiștir.

2.5. Alfapinen, terpineol, sineol, kamfor ve linelolun viyolasin üretimine etkisinin incelenmesi

C. violaceum suşunda viyolasin adlı pigmentin üretimi çevreyi algılama sisteminin kontrolü altında gerçekleşmektedir. C. violaceum 026 ve $C$. violaceum VIR07 suşları mutant suşlardır ve doğal olarak viyolasin pigmentini üretememektedir. Ancak ortama C. violaceum CV026 için kısa zincirli (C4-C8) ve C. violaceum VIR07 için uzun zincirli (C12) sinyal molekülleri eklendiği zaman viyolasin üretimi gerçekleșmektedir $[9,10] . \mathrm{Bu}$ özelliklerinden faydalanılarak C. violaceum 026 ve $C$. violaceum VIR07 suşları ortama sinyal molekülü eklenerek viyolasin üretimi için uyarılmakta ve potansiyel çevreyi algılama sistemi inhibitörü olduğu düşünülen moleküllerin test ortamına eklenmesiyle pigment üretimindeki inhibisyon incelenmektedir.

C. violaceum 026, C. violaceum VIR07 suşları sıvı besiyerinde $14-16$ saat $30^{\circ} \mathrm{C}$ 'de üretilmiștir. $5 \mathrm{ml} \mathrm{LB}$ sıvı besiyeri içerisine öncelikle sinyal molekülleri eklenmiştir. VIR07 için OdDHL sinyal molekülünden 026 için ise OHHL sinyal molekülünden ilave edilerek viyolasin üretimi sağlanmıştır. Test ortamına son derișimleri sineol ve alfa pinen; $2 \mathrm{mM}, 1 \mathrm{mM}, 0,5 \mathrm{mM}$, kamfor; 0,5mM 0,25mM, 0,125mM, terpineol; 0,1mM, $0,05 \mathrm{mM}, 0,025 \mathrm{mM}$ linelol; 0,125mM, 0,0625mM, $0,03125 \mathrm{mM}$ olacak şekilde eklenmiş, bakteri kültürlerinden ilave edilerek $30^{\circ} \mathrm{C}$ 'de çalkalamalı inkübatörde (120rpm) 18-24 saat inkübasyona bırakılmıștır. İnkübasyon sonunda șișeler vortekslenerek 1'er ml kültür tüplere alınarak 13.000 rpm'de $10 \mathrm{dk}$. santrifüjlenmiştir. Santrifüj sonunda üst faz atılarak alt kısımda kalan pellet üzerine $1 \mathrm{ml}$ dimetil sülfoksit (DMSO) ilave edilmiștir. Vorteks işleminden sonra tüpler santrifüjlenerek üst faz spektrofotometre küvetine aktarılmış 585 nm'de absorbans değerleri okunarak kaydedilmiștir [14]. Deneyler 3 kez tekrarlanarak ortalamaları alınarak sonuçlar kullanılmıștır.

\subsection{Kayma testi}

Kayma hareketi testi için $P$. aeruginosa suşları bir gece Luria-Bertani besiyerinde $37^{\circ} \mathrm{C}$ 'de üretilmiștir. Her bir kültür, $8 \mathrm{~g}$ nutrient broth $\mathrm{l}^{-1}, 5 \mathrm{~g}$ bakto agar $\mathrm{l}^{-1}$ ve $\% 0.5$ glikoz içeren kayma besiyerine (alfapinen, terpieneol, sineol, linelol, kamfor $2 \mathrm{mM}, 1 \mathrm{mM}, 0.5 \mathrm{mM}$ olacak şekilde eklenmiş) içeren petrilere ilave edilmiş ve $37^{\circ} \mathrm{C}^{\prime}$ de $18-24$ saat inkübasyona bırakılmıștır [15]. Kayma hareketi, inokülasyonun yapıldığı noktadan çevreye doğru yayılmanın çapının ölçülmesiyle test edilmiștir. Test sırasında LB negatif kontrol olarak kullanılmıştır. Deneyler 3 kez tekrarlanarak ortalamaları alınarak sonuçlar kullanılmıştır.

\subsection{Elastaz aktivitesi}

Elastaz üretim testi, Elastin Congo Red (ECR:Sigma) testi ile incelenmiştir [16]. Test edilecek bakteri suşları LB besiyerinde $37^{\circ} \mathrm{C}^{\prime} \mathrm{de} \quad 18-24$ saat üretilmiştir. $P$. aeruginosa kültürleri absorbans değerleri $600 \mathrm{~nm}$ 'de 0.02 olacak șekilde bulanıkları ayarlanıp içerisine derişimleri $2 \mathrm{mM}, 1 \mathrm{mM}, 0,5 \mathrm{mM}$ olacak şekilde alfapinen, terpieneol, sineol, linelol, kamfor eklenmiş, $37^{\circ} \mathrm{C}$ 'de 14 saat boyunca çalkalamalı inkübatörde 120 rpm'de inkübasyona bırakılmıstır. İnkübasyon sonunda $100 \mu \mathrm{l}$ bakteri süpernatant1, $20 \mathrm{mg}$ ECR ihtiva eden $900-\mu \mathrm{l}$ ECR tamponu (100 mM Tris, $1 \mathrm{mM} \mathrm{CaCl2}, \mathrm{Ph} 7,5)$ ile karıștırılarak ve $37^{\circ} \mathrm{C}$ 'de 3 saat inkübe edilmiștir. ECR santifüjlenerek süpernatantın absorbansı 495 nm'de okunmuştur. Deneyler 3 kez tekrarlanarak ortalamaları alınarak sonuçlar kullanılmıştır.

\subsection{Piyosiyanin testi}

Piyosiyanin üretimi testi için bakteri suşları LB besiyerinde $37^{\circ} \mathrm{C}^{\prime} \mathrm{de} \quad 18-24$ saat üretilmiştir. $P$. aeruginosa kültürleri $(600 \mathrm{~nm} 0.02)$ piyosiyanin broth (PB) besiyerine ekilmiş ve içerisine derişimleri $2 \mathrm{mM}$, $1 \mathrm{mM}, 0,5 \mathrm{mM}$ olacak șekilde alfapinen, terpineol, sineol, linelol, kamfor eklenerek $37^{\circ} \mathrm{C}^{\prime}$ de 16 saat çalkalanarak üretilmiștir. $\mathrm{PB}$ ortamında üretilen $P$. aeruginosa kültürünün $5 \mathrm{~mL}$ si $5 \mathrm{~mL}$ kloroform ile ekstrakte edilmiş ve organik faz ayrılmıștır [17]. Ayrılan faza $2 \mathrm{~mL} 0.2 \mathrm{M} \mathrm{HCl}$ ilave edilerek piyosiyanin miktarı OD 520 nm'de okunarak sonuçlar kayıt edilmiştir. Deneyler 3 kez tekrarlanarak ortalamaları alınarak sonuçlar kullanılmıştır. 


\subsection{Biyofilm testi}

Biyofilm testi için, $1 \mathrm{ml} P$. aeruginosa kültürü (OD600=1.0) \%1 (v/v) LB içeren $2 \mathrm{ml}$ hacminde tüplere eklenmiştir. Son derişimleri $2 \mathrm{mM}, 1 \mathrm{mM}$, $0,5 \mathrm{mM}$ olacak şekilde alfapinen, terpieneol, sineol, linelol, kamfor eklenmiştir. Tüpler çalkalanarak $37^{\circ} \mathrm{C}$ de 1 gün inkübe edilip, inkübasyon süresi sonunda kültürler dökülerek ve tüpler steril saf su ile $3 \mathrm{kez}$ yıkanmıștır. Tüpler oda sıcaklığında kurutulduktan sonra $1 \mathrm{ml} \% 0.5(\mathrm{w} / \mathrm{v})$ kristal viyole ile 30 dakika boyanarak ve steril saf su ile boyanın fazlası yıkanmıștır. Tüplere eklenen $1 \mathrm{ml} \% 95$ (v/v) etanolün $520 \mathrm{~nm}$ için absorbansı okunarak biyofilm oluşumu incelenmiştir[18]. Deneyler $3 \mathrm{kez}$ tekrarlanmış ve sonuçlar değerlendirilmiştir.

\subsection{0. İstatiksel analiz}

Elde edilen verilerin istatistiksel analizleri için tek yönlü varyans (one way Anova) testi kullanılmıștır.

\section{Bulgular}

Çalışma için tercih edilen adaçayı, defne, mersin, ardıç uçucu yağ örneklerinin, bakterilerde hücreler arası iletişim sistemine potansiyel etkilerinin olduğu tespit edilmiş ve etkiyi sağlayan etken maddenin belirlenebilmesi için GC-MS ile bileșen analizi yapılmıştır. GC-MS Analiz Sonuçları

GC-MS analiz sonuçlarına göre yağ örneklerinde yüzdece fazla bulunan etken maddeler (alfa pinen, terpineol, sineol, kamfor ve linelol) diğer bakteriler için test edilmek üzere seçilmiştir (Tablo 2).

\section{Alfa pinen, Terpineol, Sineol, Kamfor ve Lineolün Antibakteriyel Özellikleri}

Uçucu yağ örneklerinin MíK değerleri $C$. violaceum CV026, C. violaceum VIR07 suşu için alfapinen $2 \mathrm{mM}$, linelol $0.125 \mathrm{mM}$, sineol $2 \mathrm{mM}$, terpineol $0.1 \mathrm{mM}$, kamfor $0.5 \mathrm{mM}$ derişimde; $P$. aeruginosa PA01, $P$. aeruginosa PAC-1 için ise alfa pinen, terpineol, kamfor, sineol, linelol $2 \mathrm{mM}$ derişim için antibakteriyel etkisinin olmadığı belirlenmiștir.

\section{Alfapinen, Terpineol, Sineol, Kamfor ve Linelolün Viyolasin Üretimine Etkileri}

Alfapinen, terpineol, sineol, kamfor, ve linelolun farklı derişimlerde $C$. violaceum 026 ve $C$. violaceum VIR07 suşu için viyolasin pigment üretimi üzerine inhibisyon etkileri araştırılmıştır. Bu üretim OHHL ve OdDHL sinyal molekülerinin varlı̆ğında gerçekleşmektedir.

C. violaceum 026 ve VIR07 suşları için viyolasin üretimini sırasıyla terpineolün; \%75-81; \% 51-62 kamforun \% 65-81; \% 49-77 ve alfa pinenin \% 40-34;
\% 61-85 yüksek oranda inhibe ettiği tespit edilmiştir (Şekil 1a-b).

Tablo 2. Adaçayı, Defne, Mersin, Ardıç uçucu yă̆ örneklerinin \% bileșeni

\begin{tabular}{|l|l|l|l|l|}
\hline \multirow{2}{*}{ BiLEȘENLER } & defne & ardiç & adaçayl & mersin \\
\cline { 2 - 5 } & \% oran & \% oran & \% oran & \%oran \\
\hline Alfa-pinen & 4.65 & 96.0 & 7.04 & $*$ \\
\hline Beta-pinen & 3.42 & 1.21 & 1.19 & $*$ \\
\hline kamfor & 0.16 & 0.26 & 6.45 & $*$ \\
\hline sabinen & 7.21 & $*$ & 1,01 & $*$ \\
\hline mirsen & 0.54 & 1.51 & 2.53 & $*$ \\
\hline alfa-terpinen & 0.27 & $*$ & $*$ & $*$ \\
\hline limonen & 1.14 & 0.71 & 5.85 & 4.9 \\
\hline 1,8-sineol & 59.3 & & 12.6 & 6.2 \\
\hline gama-terpinen & 0.72 & $*$ & $*$ & $*$ \\
\hline simen & 1.03 & 0.32 & 1.51 & $*$ \\
\hline linelol & 1.25 & $*$ & 2.86 & 9.05 \\
\hline $\begin{array}{l}\text { 3,7-oktadiyen-2- } \\
\text { ol, 2,6-dimetil }\end{array}$ & 0.82 & $*$ & $*$ & $*$ \\
\hline $\begin{array}{l}\text { Linalil } \\
\text { Propiyonat }\end{array}$ & 0.32 & $*$ & $*$ & $*$ \\
\hline $\begin{array}{l}\text { 3sikloheksen-1- } \\
\text { mentol, alfa- } \\
\text { alfa4-trimetil } \\
\text { asetat }\end{array}$ & & & & $*$ \\
\hline Geranil asetat & 0.16 & $*$ & $*$ & $*$ \\
\hline Metil Öjenol & 0.72 & $*$ & $*$ & \\
\hline alfa-tujon & $*$ & $*$ & 30.8 & $*$ \\
\hline beta-tujon & $*$ & $*$ & 3.73 & $*$ \\
\hline kamfor & $*$ & $*$ & 15.7 & 3.01 \\
\hline Selinen & $*$ & $*$ & 4.02 & $*$ \\
\hline Borneol & $*$ & $*$ & 1.79 & $*$ \\
\hline 1,4-sineol & $*$ & $*$ & $*$ & 1.06 \\
\hline o-simen & $*$ & $*$ & $*$ & 1.58 \\
\hline alfa terpinolen & $*$ & $*$ & $*$ & 0.57 \\
\hline linalil asetat & $*$ & $*$ & $*$ & 7.06 \\
\hline l-terpinenol & $*$ & $*$ & $*$ & 4.56 \\
\hline D-fenil alkol & $*$ & $*$ & $*$ & 2.49 \\
\hline trans-karyofillen & $*$ & $*$ & $*$ & 0.68 \\
\hline 1-2 propandiyol & $*$ & $*$ & $*$ & 3.88 \\
\hline terpinen-4-ol & $*$ & $*$ & $*$ & 2.31 \\
\hline beta terpineol & $*$ & $*$ & $*$ & 4.42 \\
\hline isoborneol & $*$ & $*$ & $*$ & 1.93 \\
\hline alfa terpineol & $*$ & $*$ & $*$ & 40.6 \\
\hline benzil alkol & $*$ & $*$ & $*$ & \\
\hline Timol & $*$ & $*$ & $*$ & \\
\hline
\end{tabular}

\section{Alfapinen, Terpineol, Sineol, Kamfor ve Linelolün P. aeruginosa Kayma Hareketine Etkileri}

Bu çalışma da alfa pinen, terpineol, sineol, kamfor, ve linelolün $P$. aeruginosa PA01 ve $P$. aeruginosa PAC-1 için kayma hareketi üzerindeki etkileri incelenmiștir (Şekil 2).

Alfa pinen, kamfor, sineol, terpineol ve linelol son derişimleri $1 \mathrm{mM}$ olacak şekilde kayma besiyerine eklendiğinde, $P$. aeruginosa PA01 suşu için kayma hareketini en yüksek oranda terpineolün $(\% 70)$ ve en düşük oranda sineolün (\%46) inhibe ettiği tespit edilmiştir (Şekil 2a-f). P. aeruginosa PAC-1 için kayma hareketini terpineolün \%31 ve kamforun \%5 oranında azalttığı tespit edilmiştir. 

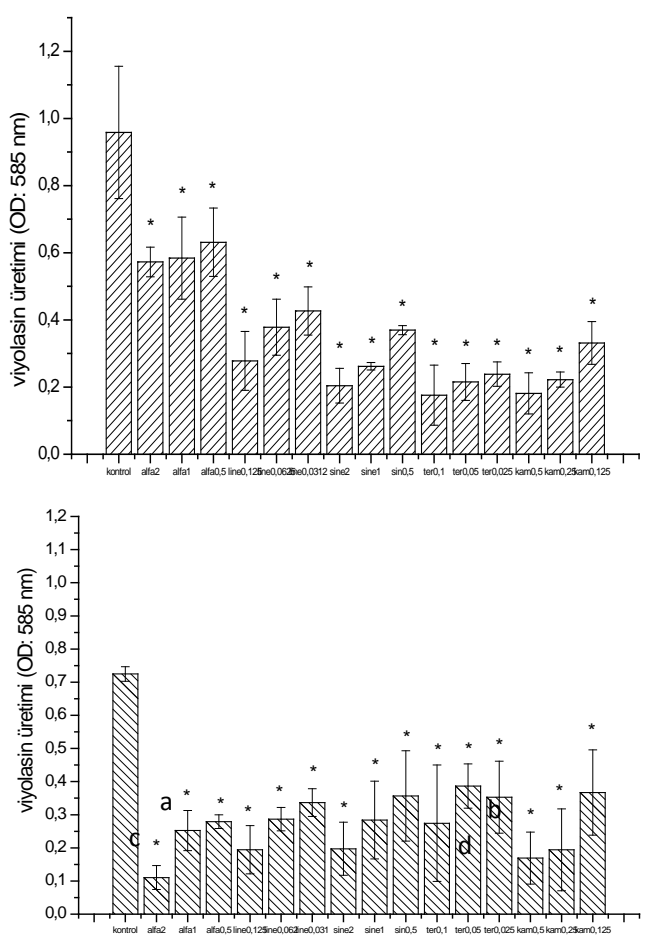

Şekil 1. Alfa pinen, terpineol, sineol, kamfor ve linelolun $C$. violaceum 026 (a) ve VIR07 (b) suşlarının viyolasin üretimine etkileri. Sonuçlar One way Anova ile analiz edilmiş (*) ile işaretli sonuçlar ile kontrol arasındaki fark $\mathrm{p}<0,05$ seviyesinde istatistiksel olarak anlamlı bulunmuştur.
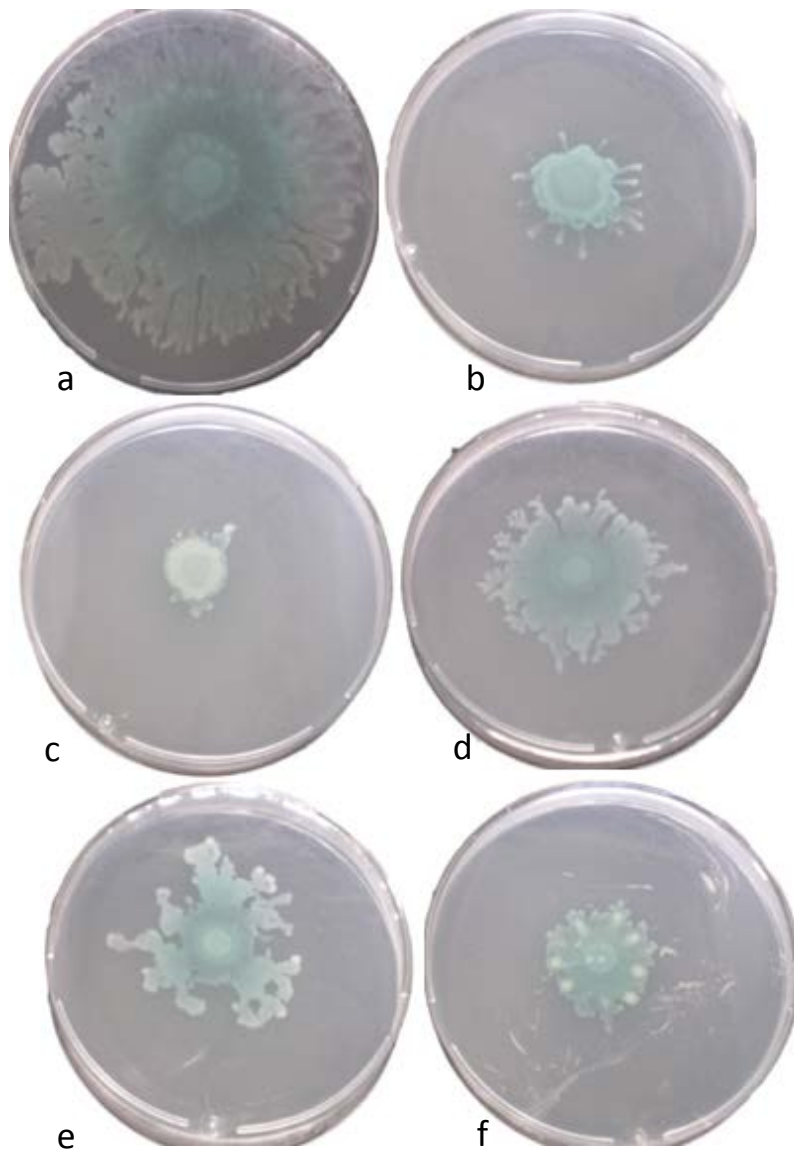

Şekil 2. P. aeruginosa PA01 için kontrol (a), $1 \mathrm{mM}$ alfa pinen (b), 1mM terpineol (c), $1 \mathrm{mM}$ sineol (d), $1 \mathrm{mM}$ kamfor (e), $1 \mathrm{mM}$ lineol (f) varlığında kayma hareketi.

\section{Alfapinen, Terpineol, Sineol, Kamfor ve Linelolun Elastaz Üretimine Etkileri}

Bu çalışmada 2, 1 ve $0.5 \mathrm{mM}$ alfa pinen, kamfor, sineol, terpineol ve linelolün, $P$. aeruginosa PA01, $P$. aeruginosa $\mathrm{PAC}-1$, için elastaz üretimine etkileri test incelenmiştir. $P$. aeruginosa PA01 ve $P$. aeruginosa PAC-1 için elastaz üretimini, ortama $2 \mathrm{mM}$ alfa pinen, kamfor, sineol, terpineol ve linelolün eklendiği zaman sirasıyla; kamfor \%49; \%39, sineol \%48; \%39, linelol $\% 43$; $\% 44$, alfapinen $\% 41$ ve terpineol $\% 41 ; \% 42$ oranında inhibe etmiştir (Şekil 3).

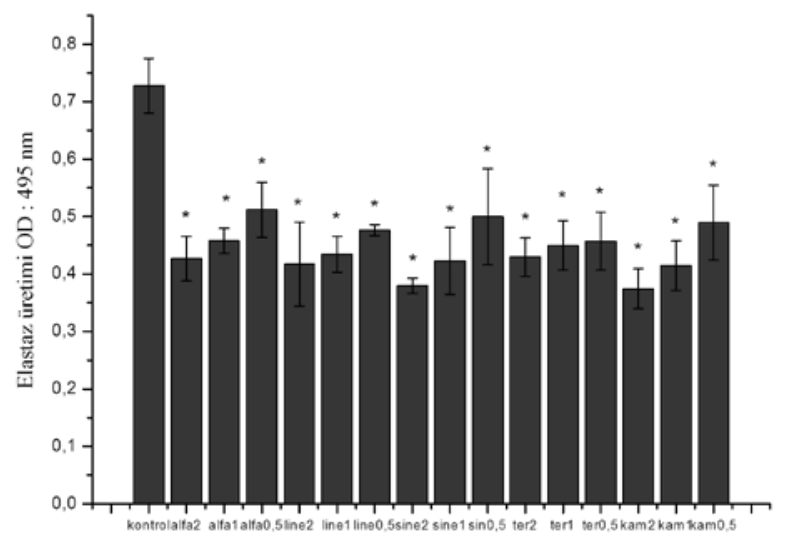

a)

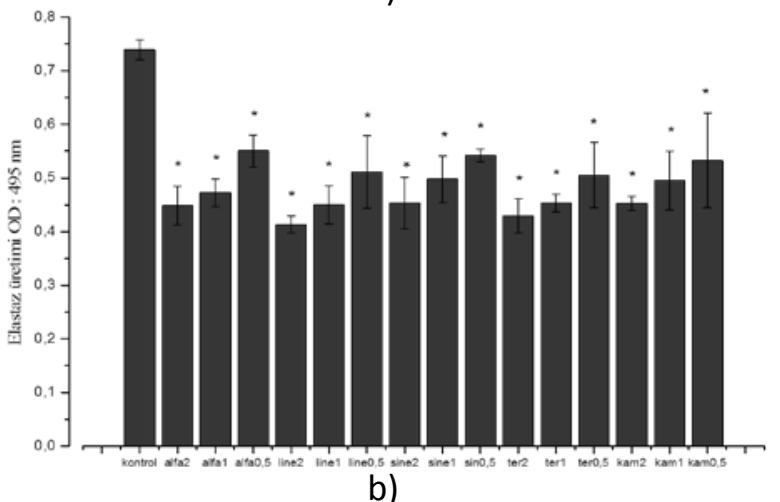

Şekil 3. P. aeruginosa PA01 (a), P. aeruginosa PAC-1 (b) için elastaz üretimine alfa pinen, kamfor, sineol, terpineol ve linelolün (2, 1 ve $0.5 \mathrm{mM}$ için) etkisi. Sonuçlar One way Anova ile analiz edilmiş (*) ile işaretli sonuçlar ile kontrol arasındaki fark $\mathrm{p}<0,05$ seviyesinde istatistiksel olarak anlamlı bulunmuştur.

\section{Alfapinen, Terpineol, Sineol, Kamfor ve Linelolün $P$. aeruginosa PA01, P. aeruginosa PAC-1 için Piyosiyanin Üretimine Etkileri}

Piyosiyanin üretimi bakımından test ortamına alfa pinen, kamfor, sineol, terpineol ve linelol 2,1 ve 0.5 $\mathrm{mM}$ son derişimde eklenerek $P$. aeruginosa PA01, $P$. aeruginosa PAC-1 inhibisyon etkileri test edilmiștir. 2 $\mathrm{mM}$ son derişim için $P$. aeruginosa PA01 ve $P$. aeruginosa $\mathrm{PAC}-1$ için piyosiyanin üretimini sırasıyla; kamfor \%48; \%53, sineol \%49; \%66, linelol \%76; $\% 55$, alfapinen $\% 56$; $\% 53$ ve terpineol $\% 60$; $\% 51$ oranında inhibe ettiği tespit edilmiștir (Șekil 4). 


\section{Alfapinen, Terpineol, Sineol, Kamfor ve Linelolun $P$. aeruginosa PA01, $P$. aeruginosa PAC-1 için Biyofilm Oluşumuna Etkileri}

P. aeruginosa PA01 ve $P$. aeruginosa PAC-1 için biyofilm oluşumunu, $2 \mathrm{mM}$ son derişim için sırasıyla; kamfor $\% 25$; \%30, sineol \%24; \%29, linelol \%8; \%20, alfapinen \%18; \%29 ve terpineol \%13; \%33 oranında inhibe ettiği tespit edilmiştir.

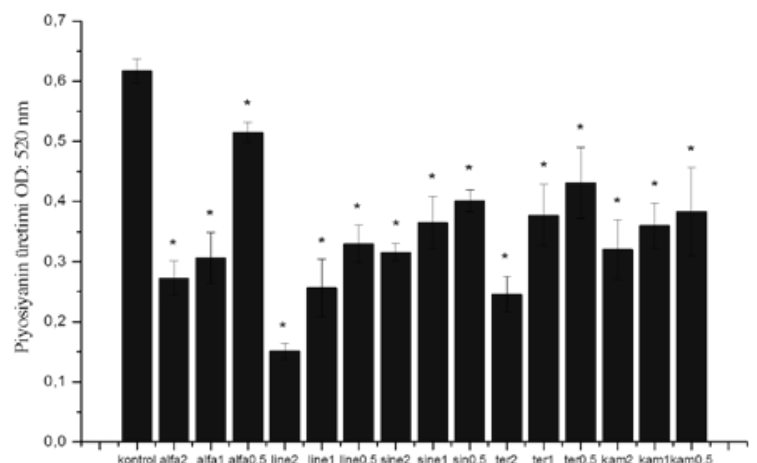

a)

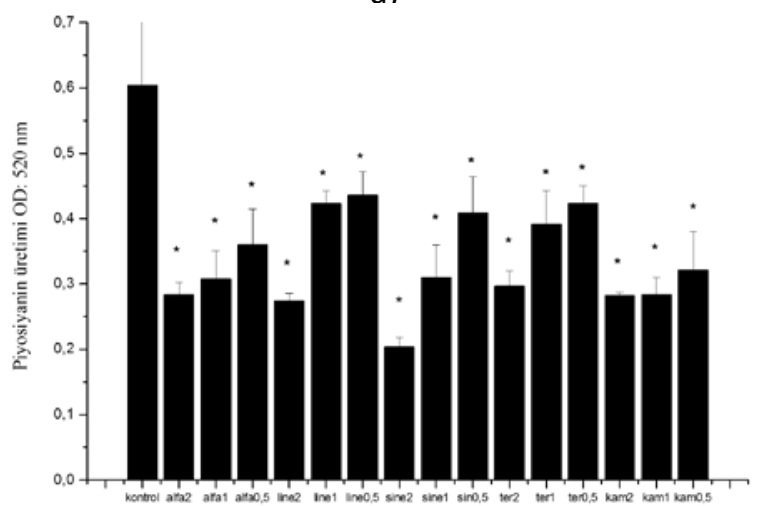

b)

Şekil 4. P. aeruginosa PA01 (a), P. aeruginosa PAC-1 (b) için piyosiyanin üretimine alfa pinen, kamfor, sineol, terpineol ve linelolün $(2,1$ ve $0.5 \mathrm{mM}$ için) etkisi. Sonuçlar One way Anova ile analiz edilmiș ( ${ }^{*}$ ) ile ișaretli sonuçlar ile kontrol arasındaki fark $\mathrm{p}<0,05$ seviyesinde istatistiksel olarak anlamlı bulunmuștur.

\section{Tartışma ve Sonuç}

Günümüzde klinik uygulamalarda çoklu ilaç direncine sahip bakteriyel suşların artması, bakteriyel enfeksiyonların tedavisi için yeni stratejiler bulunmasını gerekli kılmaktadır. Ayrıca alternatif tıbba duyulan ilginin artmasıyla, çeşitli amaçlarla kullanılan bitkisel ürünlerin antibakteriyel, antienflamatuvar gibi özellikleri çok sayıda çalışmaya konu olmuştur [12].

Pseudomonas dahil pek çok patojen bakteri, üretmiş oldukları sinyal molekülleri aracılığı ile birbirleri ile iletişim kurmakta, ortamdaki popülasyon yoğunluklarını izlemekte ve yeterli çoğunluğa ulaştıkları anda da virülens faktörlerinin sentezi gibi kritik gen ekspresyonlarını tetiklemektedir. Böylece, konağın bağışıklık sistemini zamanından önce uyarmayarak, başarılı bir enfeksiyon oluşturmaktadır. Çevreyi algılama sisteminin yönlendirilmesi ve modifiye edilmesiyle, bakteri hücrelerinin doğrudan öldürülmeden etkili olması, antibiyotiklerde gözlenen direnç gelişimine neden olmaması açısından bir avantajdır [1].

$\mathrm{Bu}$ nedenle patojen bakterilerilerde çevreyi algılama sistemi modifiye edilmesi veya yönlendirilmesine yönelik pek çok molekülün etkisini konu alan artan sayıda çalışma mevcuttur [14, 19-24]. Ancak mevcut çalıșmalarda rapor edilen moleküllerin toksik olması, etki göstermesi için yüksek derişimde vücuda alınmasının gerekmesi, in vivo stabilitelerinin düşük olması gibi pek çok olumsuz özellikleri mevcuttur. Bu nedenle hala bakterilerde hücreler arası iletişim sistemini bozabilecek veya yönlendirebilecek toksik olmayan, doğal inhibitör moleküllerin tespitine ihtiyaç duyulmaktadır.

$\mathrm{Bu}$ amaçla bu çalıșmada zaten etnobotanik amaçla halk arasında kullanılan bazı uçucu yağ örneklerinin etken maddelerinin bu potansiyeli incelenmiştir. Öncelikle potansiyel etkileri incelenmiş ve alfa pinen viyolasin üretiminde $C$. violaceum VIR07 için \%84.8, terpineol ise $C$. violaceum 026 için \%81.6 oranında inhibisyona sebep olmuştur.

Elastaz, elastin ve kollajen gibi ökaryotik proteinleri parçalayan bir metalloproteazdır [25]. Elaztaz las $B$ geni tarafından kodlanır. las $B$ geni, LasR-LasI çevreyi algılama sisteminin kontrolündeki LasR regülatörü tarafindan kontrol edilir [26].

P. aeruginosa PA01 sușunda elastaz üretimini en yüksek inhibisyonu \%49 ile kamfor ve $P$. aeruginosa PAC-1 klinik izolatında ise en yüksek inhibisyonu $\% 44$ oranla linelol göstermiştir.

Piyosiyanin mavi renkli, kloroformda eriyen bir pigmenttir. $P$. aeruginasa tarafından üretilir, bakterinin fizyolojisinde ve patojenezinde önemli rol oynar. Piyosiyanin üretimi, doğrudan rhl sistemi tarafından kontrol edilirken; LasA üretimi las sistemi tarafından kontrol edilir [27, 28]. Ancak çevreyi algılama sistemindeki hiyerarşiden dolayı las sisteminin aynı zamanda piyosiyanin üretimini de etkilediği bilinmektedir [27].

P. aeruginosa PA01 suşunda linelol, piyosiyanin üretimini \%76 oranında inhibe ettiği gözlenirken, $P$. aeruginosa PAC-1 izolatında ise \%66 oranda sineol'un inhibisyon etkisi gözlenmiştir.

Yine 1mM derişimde terpineolün P. aeruginosa PA01 için kayma hareketini $\% 70$ ve $P$. aeruginosa PAC-1 klinik izolatında ise \%31 oranında inhibe ettiği belirlenmiştir.

Literatürde $P$. aeruginosa'nın temel virülans faktörlerinden olan biyofilm yapının, antibiyotik 
geçişinde bariyer görevi görerek bakteri direncine katkı sağladığı bilinmektedir[29, 30]. Bu çalışmada alfapinen, kamfor, sineol, terpineol, ve linelol'un $P$. aeruginosa PA01 suşunda ve $P$. aeruginosa PAC-1 klinik izolatında biyofilm oluşumuna etkileri araştırılmış ancak etken madde uygulanmamış örneklere göre istatiksel olarak önemli inhibisyona sebep olmadıkları tespit edilmiştir.

Çalışma sonuçlarına göre alfapinen, kamfor, sineol, terpineol ve linelolün viyolasin üretimini neredeyse tamamen inhibe etmesine rağmen (Şekil1.), $P$. aeruginosa PA01 ve $P$. aeruginosa PAC-1 klinik izolatında virülens faktörlerinin üretimi daha az oranda inhibe ettiği (Şekil 2,3,4) tespit edilmiştir. Dahası özellikle biyofilm oluşumu için inhibisyon oranları oldukça düşüktür. Çalışma sonucunda etkisi incelenen etken maddeler arasinda terpineol ve sineolün virülens faktörlerinin üretimini en yüksek oranda inhibe ettiği tespit edilmiştir. Bu çalışmayla günlük hayatta sıklıkla kullanılan yağ örneklerinin bileşiminde bulunan etken maddelerin, bakterilerde hücreler arası iletişim sistemini farklı oranlarda etkileyerek inhibitör etki gösterdikleri tespit edilmiştir. Ayrıca aynı etken maddeler farklı yağ örneklerinde ve aynı karışım içerisinde farklı oranlarda farklı etken maddeler ile birlikte bulunmaktadır. Bu değişkenlerin hepsi örneklerin etki potansiyelini değiştirmektedir. Çalışmanın sonucunda bu etken maddelerin, bu iletişim sistemini kullanan patojen bakterilerin neden olduğu çeşitli enfeksiyonların tedavisi ve kontrol edilmesi ve bu amaçla yeni ürünlerin geliştirilmesi için fayda sağlanabileceği düşünülmektedir.

\section{Teşekkür}

Bu çalışmayı 2575-M-10 No'lu Proje ile maddi olarak destekleyen Süleyman Demirel Üniversitesi Bilimsel Araştırma Projeleri Yönetim Birimi Başkanlığı'na teşekkür ederiz.

\section{Kaynakça}

[1] Rasmussen, T. B., Givskov, M. 2006. Quorum sensing inhibitors: a bargain of effects. Microbiology 152, 895-904.

[2] Fuqua, C., Winans, S.C., Greenberg, E.P. 1996. Census and consensus in bacterial ecosystems: the LuxR-LuxI family of quorum-sensing transcriptional regulators. Annual Reviews in Microbiology 50, 727-751.

[3] McGowan, S.J., Barnard, A.M., Bosgelmez, G., Sebaihia, M., Simpson, N.J., Thomson, N.R., Todd, D.E., Welch, M., Whitehead, N.A., Salmond, G.P. 2005. Carbapenem antibiotic biosynthesis in Erwinia carotovora is regulated by physiological and genetic factors modulating the quorum sensing-dependent control pathway. Molecular microbiology 55, 526-545.
[4] Hentzer, M., Givskov, M., Parsek, M.R. 2002. Targeting quorum sensing for treatment of chronic bacterial biofilm infections. Laboratory Medicine 33, 295-306.

[5] Parsek, M.R., Greenberg, E.P. 2000. Acylhomoserine lactone quorum sensing in gramnegative bacteria: a signaling mechanism involved in associations with higher organisms. Proceedings of the National Academy of Sciences 97, 8789-8793.

[6] Parsons, J.F., Greenhagen, B.T., Shi, K., Calabrese, K., Robinson, H., Ladner, J.E. 2007. Structural and functional analysis of the pyocyanin biosynthetic protein PhzM from Pseudomonas aeruginosa. Biochemistry 46, 1821-1828.

[7] Van Delden, C., Iglewski, B.H. 1998. Cell-to-cell signaling and Pseudomonas aeruginosa infections. Emerging infectious diseases 4, 551.

[8] Williams, P., Camara, M., Hardman, A., Swift, S., Milton, D., Hope, V.J., Winzer, K., Middleton, B., Pritchard, D.I., Bycroft, B.W. 2000. Quorum sensing and the population-dependent control of virulence. Philosophical Transactions of the Royal Society of London B: Biological Sciences $355,667-680$.

[9] McClean, K.H., Winson, M.K., Fish, L., Taylor, A., Chhabra, S.R., Camara, M., Daykin, M., Lamb, J.H., Swift, S., Bycroft, B.W. 1997. Quorum sensing and Chromobacterium violaceum: exploitation of violacein production and inhibition for the detection of $\mathrm{N}$-acylhomoserine lactones. Microbiology 143, 3703-3711.

[10] Morohoshi, T., Kato, M., Fukamachi, K., Kato, N., Ikeda, T. 2008. N-acylhomoserine lactone regulates violacein production in Chromobacterium violaceum type strain ATCC 12472. FEMS microbiology letters 279, 124-130.

[11] Bjarnsholt, T., Jensen, P.Ø., Rasmussen, T.B., Christophersen, L., Calum, H., Hentzer, M., Hougen, H.-P., Rygaard, J., Moser, C., Eberl, L. 2005. Garlic blocks quorum sensing and promotes rapid clearing of pulmonary Pseudomonas aeruginosa infections. Microbiology 151, 3873-3880.

[12] Cavanagh, H., Wilkinson, J. 2002. Biological activities of lavender essential oil. Phytotherapy Research 16, 301-308.

[13] Hammer, K.A., Carson, C., Riley, T. 1999. Antimicrobial activity of essential oils and other plant extracts. Journal of applied microbiology 86, 985-990.

[14] Choo, J., Rukayadi, Y., Hwang, J.K. 2006. Inhibition of bacterial quorum sensing by vanilla extract. Letters in Applied Microbiology 42, 637 641. 
[15] Rashid, M.H., Kornberg, A. 2000. Inorganic polyphosphate is needed for swimming, swarming, and twitching motilities of Pseudomonas aeruginosa. Proceedings of the National Academy of Sciences 97, 4885-4890.

[16] Ohman, D., Cryz, S., Iglewski, B. 1980. Isolation and characterization of Pseudomonas aeruginosa PAO mutant that produces altered elastase. Journal of Bacteriology 142, 836-842.

[17] Essar, D., Eberly, L., Crawford, I. 1990. Evolutionary differences in chromosomal locations of four early genes of the tryptophan pathway in fluorescent pseudomonads: DNA sequences and characterization of Pseudomonas putida trpE and trpGDC. Journal of bacteriology 172, 867-883.

[18] Zhang, X.-S., García-Contreras, R., Wood, T.K. 2008. Escherichia coli transcription factor YncC (McbR) regulates colanic acid and biofilm formation by repressing expression of periplasmic protein YbiM (McbA). The ISME journal 2, 615-631.

[19] Bosgelmez-Tinaz, G., Ulusoy, S., Ugur, A., Ceylan, 0.2007 . Inhibition of quorum sensing-regulated behaviors by Scorzonera sandrasica. Current microbiology 55, 114-118.

[20] Khan, M.S.A., Zahin, M., Hasan, S., Husain, F.M., Ahmad, I. 2009. Inhibition of quorum sensing regulated bacterial functions by plant essential oils with special reference to clove oil. Letters in applied microbiology 49, 354-360.

[21] Salini, R., Sindhulakshmi, M., Poongothai, T., Pandian, S.K. 2015. Inhibition of quorum sensing mediated biofilm development and virulence in uropathogens by Hyptis suaveolens. Antonie van Leeuwenhoek 107, 1095-1106.

[22] Szabó, M.Á., Varga, G.Z., Hohmann, J., Schelz, Z., Szegedi, E., Amaral, L., Molnár, J. 2010. Inhibition of quorum-sensing signals by essential oils. Phytotherapy research 24, 782-786.

[23] Zhu, H., Sun, S. 2008. Inhibition of bacterial quorum sensing-regulated behaviors by Tremella fuciformis extract. Current microbiology 57, 418-422.

[24] Zhu, H., Liu, W., Tian, B., Liu, H., Ning, S. 2011. Inhibition of quorum sensing in the opportunistic pathogenic bacterium Chromobacterium violaceum by an extract from fruiting bodies of lingzhi or reishi medicinal mushroom, Ganoderma lucidum (w. Curt.: Fr.) p. Karst.(higher basidiomycetes). International journal of medicinal mushrooms 13.

[25] Hamood, A.N., Griswold, J., Colmer, J. 1996. Characterization of elastase-deficient clinical isolates of Pseudomonas aeruginosa. Infection and immunity 64, 3154-3160.
[26] Passador, L., Cook, J.M., Gambello, M.J., Rust, L., Iglewski, B.H. 1993. Expression of Pseudomonas aeruginosa virulence genes requires cell-to-cell communication. Science 260, 1127-1130.

[27] De Kievit, T.R., Iglewski, B.H. 2000. Bacterial quorum sensing in pathogenic relationships. Infection and immunity 68, 4839-4849.

[28] Rumbaugh, K.P., Griswold, J.A., Hamood, A.N. 2000. The role of quorum sensing in the in vivo virulence of Pseudomonas aeruginosa. Microbes and infection 2, 1721-1731.

[29] Anwar, H., Costerton, J. 1990. Enhanced activity of combination of tobramycin and piperacillin for eradication of sessile biofilm cells of Pseudomonas aeruginosa. Antimicrobial agents and chemotherapy 34, 1666-1671.

[30] Moskowitz, S.M., Foster, J.M., Emerson, J., Burns, J.L. 2004. Clinically feasible biofilm susceptibility assay for isolates of Pseudomonas aeruginosa from patients with cystic fibrosis. Journal of clinical microbiology 42, 1915-1922. 